\title{
Simple Electrochemical Sensor Based on Carbon-black Paste Electrode Coupled with Derivative Square Wave Voltammetry for the Determination of Sulfites in Rice Wine
}

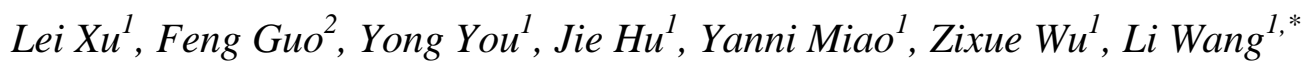 \\ ${ }^{1}$ Department of Applied Chemistry, Zhejiang Gongshang University, Hangzhou 310018, China \\ ${ }^{2}$ Narada Power Source Co., Ltd. Hangzhou 310012, China \\ *E-mail: liwang-wh@hotmail.com, liwang_wh@zjgsu.edu.cn
}

doi: $10.20964 / 2016.06 .43$

Received: 27 December 2015 / Accepted: 26 March 2016 / Published: 4 May 2016

\begin{abstract}
A simple electrochemical sensor for the determination of sulfites in rice wine samples based on carbon black paste electrode (CBE) coupled with first-order derivative square wave voltammetry (SWV) was developed. CBE prepared by packing the mixture of carbon black powder and liquid paraffin oil with a ratio of $2: 1(\mathrm{w} / \mathrm{w})$ into a cavity without any additional modification was reported. The cyclic voltammetry and SWV showed that the oxidation current of sulfite at CBE increased significantly compared with bare glassy carbon electrode or graphite paste electrode. Through firstorder derivative processing, peaks became narrower and sharper leading to the enhancement of sensitivity. External standard calibration curve was in the range of $0.008 \sim 1.0 \mathrm{mmol} \mathrm{L}^{-1}$ with a detection limit of $6.0 \mu \mathrm{mol} \mathrm{L}{ }^{-1}$. This method was applied to the determination of sulfites in the commercial available rice wine samples and the results were compared with a titration method.
\end{abstract}

Keywords: Electrochemical sensor; Carbon black paste electrode; Derivative square wave voltammetry; Sulfite determination; Rice wine

\section{FULL TEXT}

(C) 2016 The Authors. Published by ESG (www.electrochemsci.org). This article is an open access article distributed under the terms and conditions of the Creative Commons Attribution license (http://creativecommons.org/licenses/by/4.0/). 